\title{
Design of Small-Scaled Derailment Simulator for Investigating Bogie Dynamics
}

\author{
Beom-Gyu Eom*, Bu-Byoung Kang** and Hi Sung Lee ${ }^{\dagger}$
}

\begin{abstract}
The dynamic stability of railway vehicle has long been one of the important issues in railway safety. The dynamic simulator has been used as a tool for investigating the dynamic stability of railway vehicles and wheel/rail interfaces. In particular, small scale simulators have been widely used in laboratory studies instead of full scale roller rigs which can be quite costly and rather inconvenient for testing out the effect of diverse design parameters. But techniques for design of a small scale simulator for the fundamental study about the dynamic characteristics of the wheel-rail systems and the bogie systems have not been well developed in Korea. Therefore, a research on the development of a small scale simulator for investigating bogie dynamics needs to be undertaken. The present paper investigates design of a small-scaled derailment simulator and the design of a small scale bogie. The simulator developed can be used to investigate the effect of diverse parameters such as attack angle, wheelbase and cant on dynamic behavior of the bogie and key dynamic performance parameters such as derailment coefficient and critical speed.
\end{abstract}

Keywords : Small-scaled derailment simulator, 1/5 small scaled bogie, Similarity laws, Running safety

\section{Introduction}

Operational safety of railway vehicle has long been one of the important issues to railway operating companies as well as infrastructure owners because the derailment can be lead to serious accidents. The characteristics of dynamic behavior and stability of bogie are being tested by utilizing a test equipment called "roller rig". This test equipment consists of two rollers which are equivalent to wheel and rail and is being used in an effort to test for key dynamic performance indicators in railway vehicles such as critical speed and riding comfort associated with contact between wheel and rail. However, it is difficult to perform a full scale test with the actual vehicle for testing dynamic characteristic due to high cost and time involved, as well as difficulties associated with setting up various test conditions. A small

\footnotetext{
$\dagger$ Corresponding author: Graduate School of Railroad, Seoul National University of Science \& Technology, Korea

E-mail: hslee@seoultech.ac.kr

* Graduate School of Railroad. Seoul National University of Science \& Technology, Korea

**Korea Railroad Research Institute, Korea
}

scale roller rig can be used as a way to circumvent these problems but a basic research on proper use of scaled bogie and track is needed in Korea.

Small scale derailment simulator based on similarity laws has been developed to predict dynamic behavior of railway vehicles. The scaled bogie was designed based on MAN bogie which is the motor bogie for Saemaeul and it allows testing of dynamic stability due to a change in attack angle as well as to test the effect of the wheelbase and cant on the dynamic behavior of the bogie. The small scaled derailment simulator developed here will be installed in Railway Safety Research Center at Seoul National University of Science \& Technology and is intended to use for investigating derailment safety and dynamic stability.

\section{Similarity Laws}

Various Similarity for the scaled model are proposed in accordance with its purpose of study. Similarity rules cannot be applied to all the dynamics characteristics perfectly. It can be applied to certain parameters and some parameters need to be adjusted to use. Table 1 shows how 
Table 1 Comparison of Similarity Laws

\begin{tabular}{ccccc}
\hline Scaling factor & Iwnicki & Pascal & Jaschinski & $\begin{array}{c}\text { Jaschinski } \\
\text { modified }\end{array}$ \\
\hline$\Phi_{\mathrm{l}}$ length & $\Phi$ & $\Phi$ & $\Phi$ & $\Phi$ \\
\hline$\Phi_{\mathrm{t}}$ time & 1 & $\Phi$ & $\sqrt{\Phi}$ & $\sqrt{\Phi}$ \\
\hline$\Phi_{\mathrm{f}}$ frequency & 1 & $1 / \Phi$ & $1 \sqrt{\Phi}$ & $1 \sqrt{\Phi}$ \\
\hline$\Phi_{\mathrm{v}}$ velocity & $\Phi$ & 1 & $\sqrt{\Phi}$ & $\sqrt{\Phi}$ \\
\hline$\Phi_{\mathrm{a}}$ acceleration & $\Phi$ & $1 / \Phi$ & 1 & 1 \\
\hline$\Phi_{\rho}$ density & 1 & 1 & 1 & 0.6 \\
\hline$\Phi_{\mathrm{m}}$ mass & $\Phi^{3}$ & $\Phi^{3}$ & $\Phi^{3}$ & $\Phi^{3} / 2$ \\
\hline$\Phi_{\mathrm{I}}$ inertia & $\Phi^{5}$ & $\Phi^{5}$ & $\Phi^{5}$ & $\Phi^{5} / 2$ \\
\hline$\Phi_{\mathrm{E}}$ elasticity & 1 & 1 & 1 & 3 \\
\hline$\Phi_{\mathrm{w}}$ weight & $\Phi^{3}$ & $\Phi^{3}$ & $\Phi^{3}$ & $\Phi^{3} / 2$ \\
\hline$\Phi_{\mathrm{F}}$ force & $\Phi^{4}$ & $\Phi^{2}$ & $\Phi^{3}$ & $\Phi^{3} / 2$ \\
\hline$\Phi_{\mathrm{k}}$ stiffness & $\Phi^{3}$ & $\Phi$ & $\Phi^{2}$ & $0.6 \Phi^{2}$ \\
\hline$\Phi_{\mathrm{c}}$ damping & $\Phi^{3}$ & $\Phi^{2}$ & $\Phi^{2.5}$ & $0.6 \Phi^{2.5}$ \\
\hline$\Phi_{\mu}$ friction & 1 & 1 & 1 & 1 \\
\hline
\end{tabular}

scaling factor can be adjusted to existing similarity methods such as dimension, mass, spring characteristic and material properties.

Iwnicki [1] used the same material in an effort to study stability of vehicle and characteristics of dynamic behavior and also tried scaling to other parameters setting focus of similarity rules to vibration so that the relationship between full scale model and small scale model can be specified. Pascal [1] projected a small scaled running test equipment which has larger radius of roller to verify the creep theory and contact dynamics between wheel and rail and he sets the focus of similarity rules to speed. Jaschinski [1] applied the small scaled model to prove the adequacy of nonlinear equation and multibody dynamics of railway vehicle and he tried scaling by setting the focus of similarity rules to acceleration.

However, these similarity rules have parameters that are not applied by artificial reduction method such as the modulus of elasticity for the material and acceleration of gravity and this creates phenomenon that small scale movement equation doesn't apply to similarity rules.

Therefore, it is impossible to make perfect similarity between full scale bogie and small scale bogie models. Jaschinski tried approximate similarity on characteristics of contact between wheel and rail by applying a different similarity rule that alters physical characteristics of material.

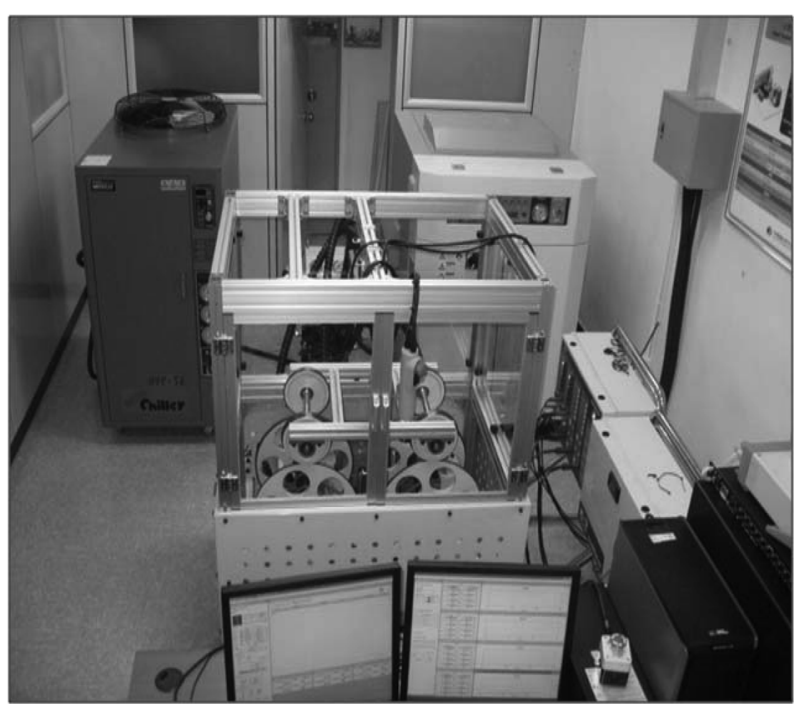

Fig. 1 Small scaled derailment simulator

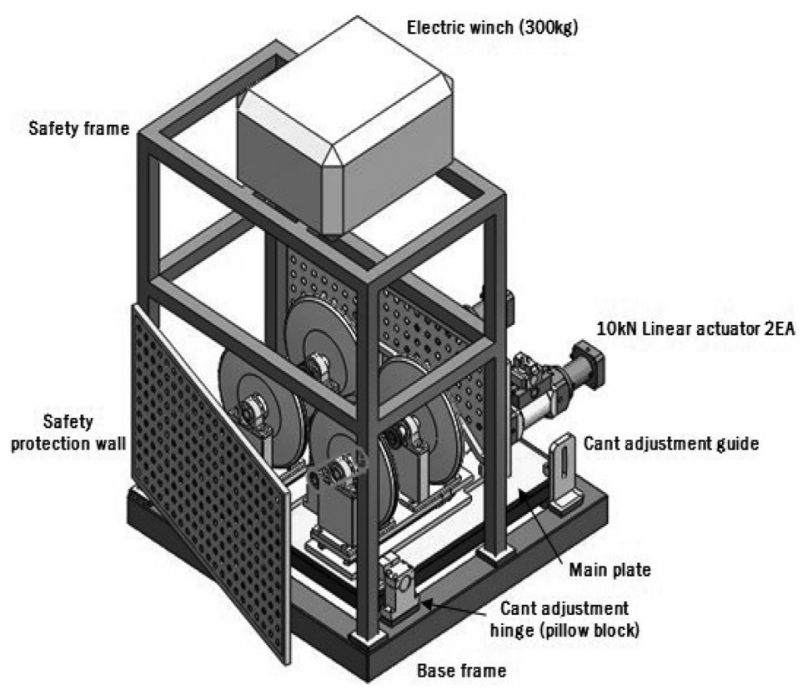

Fig. 2 Main equipment of small scaled derailment simulator

\section{Small Scaled Derailment Simulator}

\subsection{System configuration}

This small scaled derailment simulator is designed by applying Iwnicki's similarity rule and main specification is described in Table 2.

This system consists of 5 different subsystems such as main equipment that bogie seats on, HPU that generates hydraulic to running hydraulic actuator, HSM that distributes generated hydraulic into 2 actuators, chiller that cools down the lubricating oil of HPU, and controller that controls the equipment. This simulator is installed in Railway Safety Research Center in Seoul National University of 
Table 2 Specifications of Small Scaled Derailment Simulator

\begin{tabular}{|c|c|c|c|}
\hline \multicolumn{2}{|c|}{ Description } & Specification & Note \\
\hline \multicolumn{2}{|c|}{ Base frame } & $\begin{array}{l}\text { - Material : } 100 \mathrm{~mm} \times 100 \mathrm{~mm} \text { steel pipe welding frame } \\
\text { - Dimension : } 1120 \mathrm{~mm} \times 1120 \mathrm{~mm} \\
\text { - Finishing work : Painting after sanding } \\
\text { - Color: White }\end{array}$ & \\
\hline \multicolumn{2}{|c|}{ Main Motor } & $\begin{array}{l}\text { - Motor type : AC motor } \\
\text { - Power : } 220 \mathrm{~V} 3 \mathrm{P} \\
\text { - Control : controls by main control software } \\
\text { - Spindle with powerful hardness included } \\
\text { - Velocity range }: 0 \sim 1150 \mathrm{rpm} \\
\text { - Hour meter included }\end{array}$ & \\
\hline \multicolumn{2}{|c|}{ Cant adjusting equipment } & $\begin{array}{l}\text { - Range : } 0 \sim 160 \mathrm{~mm} \text { (scaled) } \\
\text { - Figure : Shape of screw or the one that is equivalent to it }\end{array}$ & \\
\hline \multicolumn{2}{|c|}{ Attacking angle adjusting equipment } & $\begin{array}{l}\text { - Range : }-3^{\circ} \sim+3^{\circ} \\
\text { - Figure : Shape of screw or the one that is equivalent to it }\end{array}$ & \\
\hline \multicolumn{2}{|c|}{ Hydraulic generating equipment } & $\begin{array}{l}\text { - Soundproof insulation and cover : below } 70 \mathrm{~dB} \\
\text { - Stainless Steel material } \\
\text { - Motor : } 6 \text { poles. Voltage : } 380 \text { or } 220 \text { Volts, } 60 \mathrm{~Hz}, 3 \text { Phase } \\
\text { - Plate type heat exchanger (Stainless Steel for anti corrosion) } \\
\text { - On/Off pressure control } \\
\text { - Cooling water Flow control by utilizing automatic control valve } \\
\text { - Embedded Filtering equipment below } 3 \text { micron } \\
\text { - Monitoring \& Alarm system (Force, Oil, Temperature, Filter, Pressure) } \\
\text { - Automatic locking devise to limit the oil temperature } \\
\text { - Reset, Remote, Power meter function } \\
\text { - Independent performance. }\end{array}$ & \\
\hline \multicolumn{2}{|c|}{ Cooling system } & $\begin{array}{l}\text { - Cooling type } \\
\text { - Power source : } 380 \text { or } 220 \mathrm{~V}, 3 \mathrm{P} \\
\text { - Distance between main frame and cooling fan : max } 20 \mathrm{~m} \\
\text { - Antifreezing liquid. } \\
\text { - Cooling fan. }\end{array}$ & \\
\hline \multirow[b]{2}{*}{ Safety equipment } & Mechanical & $\begin{array}{l}\text { - Safety Surveillance devise for both equipment and operator. } \\
\text { - System that notifies operator of abnormality of equipment. }\end{array}$ & \\
\hline & Electrical & $\begin{array}{l}\text { - EMG that stops equipment instantly in case of emergency. } \\
\text { - Devise that controls Temperature overheating. } \\
\text { - Blinker light (with Alarm function) }\end{array}$ & \\
\hline
\end{tabular}

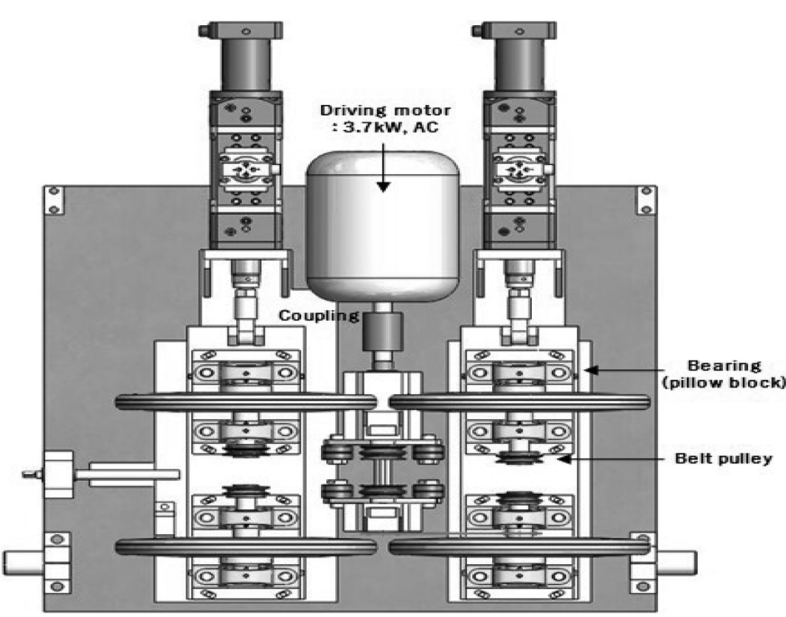

Fig. 3 Running system of small scaled derailment simulator

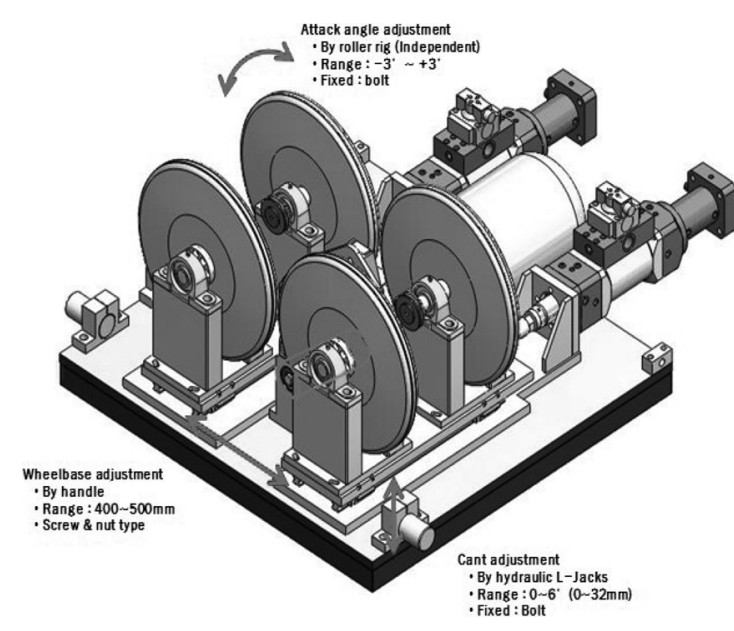

Fig. 4 Main functions of scaled derailment simulator 
Science \& Technology and Fig. 1 shows can be referred to.

The main equipment of small scaled derailment simulator, refer to Fig. 2, consists of base frame, main plate, running operation system, safety frame and electric winch. The running operation system, refer to Fig. 3, has its motor to run roller, linear guiding and roller rig module that can adjust the attack angle and hydraulic actuator to run each roller module. It runs by $\mathrm{AC}$ motor and uses the belt pulleyeach 2 line on the main running axle to convey its power independently to each roller. Belt uses link belt to act on changes of location of pully from attack angle adjustment on each roller and is able to change the length accordingly to perform tests of changing wheelbase $(100 \mathrm{~mm})$.

\subsection{Main functions of the system}

This simulator can perform test of dynamic behavior and stability in accordance with changes of attack angle, wheel base and cant from small scale bogie model and system structure is like in Fig. 4. Hydraulic L-jacks is used to adjust the height of cant and angle adjusting parts using Pillow block for the adjustment of cant. Bolts are used for fixation after adjustment of angle and the changing range for the angle is $0 \sim 6^{\circ}(0 \sim 32 \mathrm{~mm})$. Adjustment of attack angle and wheel base can be made independently to each individual roller and its adjustment angle is $\pm 3^{\circ}$ and Bolts are used for fixation. Also, wheel base adjustment is by utilizing screws and nuts along with handles.

\section{1/5 Small Scaled Bogie Design}

\subsection{Designing 1/5 small scale bogie}

In designing $1 / 5$ small scaled bogie, a bolsterless typed, MAN bogie which is the motor bogie from Samaeul.

Related information on Reference [2], which is actual

Table 3 Design Specifications of Small Scaled Bogie

\begin{tabular}{|c|c|c|c|}
\hline Description & Actual size bogie & Similarity index & Small scaled bogie $(1 / 5)$ \\
\hline Length of bogie frame $[\mathrm{m}]$ & 3.606 & $1 / \varphi$ & 0.7212 \\
\hline Width of bogie frame [m] & 2.268 & $1 / \varphi$ & 0.4536 \\
\hline Height of bogie frame $[\mathrm{m}]$ & 0.897 & $1 / \varphi$ & 0.1794 \\
\hline Wheelbase [m] & 2.5 & $1 / \varphi$ & 0.500 \\
\hline Diameter of wheel [m] & 0.914 & $1 / \varphi$ & 0.1828 \\
\hline Mass of carbody $[\mathrm{kg}]$ & 54,970 & $1 / \varphi^{3}$ & 439.76 \\
\hline Mass of bogie $[\mathrm{kg}]$ & 3,500 & $1 / \varphi^{3}$ & 28 \\
\hline Mass of wheelset $[\mathrm{kg}]$ & 2,650 & $1 / \varphi^{3}$ & 21.2 \\
\hline Gauge $[\mathrm{m}]$ & 1.435 & $1 / \varphi$ & 0.287 \\
\hline Bogie_mass moment of inertia, $\mathrm{I}_{\mathrm{xx}}\left[\mathrm{mgm}^{2}\right]$ & 1.58 & $1 / \varphi^{5}$ & 0.0005056 \\
\hline Bogie_mass moment of inertia, $\mathrm{I}_{\mathrm{yy}}\left[\mathrm{mgm}^{2}\right]$ & 1.6 & $1 / \varphi^{5}$ & 0.000512 \\
\hline Bogie_mass moment of inertia, $\mathrm{I}_{\mathrm{zz}}\left[\mathrm{mgm}^{2}\right]$ & 3.01 & $1 / \varphi^{5}$ & 0.0009632 \\
\hline Wheelset_mass moment of inertia, $\mathrm{I}_{\mathrm{xx}}\left[\mathrm{mgm}^{2}\right]$ & 0.865 & $1 / \varphi^{5}$ & 0.0004352 \\
\hline Wheelset_mass moment of inertia, $\mathrm{I}_{\mathrm{yy}}\left[\mathrm{mgm}^{2}\right]$ & 0.003 & $1 / \varphi^{5}$ & 0.00000096 \\
\hline Wheelset_mass moment of inertia, $\mathrm{I}_{\mathrm{zz}}\left[\mathrm{mgm}^{2}\right]$ & 0.865 & $1 / \varphi^{5}$ & 0.0004352 \\
\hline Primary suspension_spring constant, $\mathrm{K}_{\mathrm{x}}[\mathrm{MN} / \mathrm{m}]$ & 0.379 & $1 / \varphi^{3}$ & 0.003032 \\
\hline Primary suspension_spring constant, $\mathrm{K}_{\mathrm{y}}[\mathrm{MN} / \mathrm{m}]$ & 0.379 & $1 / \varphi^{3}$ & 0.003032 \\
\hline Primary suspension_spring constant, $\mathrm{K}_{\mathrm{z}}[\mathrm{MN} / \mathrm{m}]$ & 0.758 & $1 / \varphi^{3}$ & 0.006064 \\
\hline Primary suspension_vertical damper_damping coefficient [MNs/m] & 0.03 & $1 / \varphi^{3}$ & 0.00024 \\
\hline Primary suspension_bushing, $\mathrm{K}_{\mathrm{x}}[\mathrm{MN} / \mathrm{m}]$ & 16.0 & $1 / \varphi^{3}$ & 0.128 \\
\hline Primary suspension_bushing, $\mathrm{K}_{\mathrm{y}}[\mathrm{MN} / \mathrm{m}]$ & 4.0 & $1 / \varphi^{3}$ & 0.032 \\
\hline Primary suspension_bushing, $\mathrm{K}_{\mathrm{z}}[\mathrm{MN} / \mathrm{m}]$ & 0.142 & $1 / \varphi^{3}$ & 0.001136 \\
\hline Wheel thread profile & $1 / 40$ & $1 / \varphi$ & - \\
\hline Roller head profile & $60 \mathrm{Kg}$ & $1 / \varphi$ & - \\
\hline Young's modulus $\left[\mathrm{N} / \mathrm{m}^{2}\right]$ & $2.07 \mathrm{E} 11$ & $1 / 1$ & $2.07 \mathrm{E} 11$ \\
\hline
\end{tabular}


figure and technical drawings from Samaeul motor bogie has been referred. Small scaled bogie was designed according to the similarity rules for MAN bogie, Saemaeul motor bogie and it consists of 2 wheel base, bogie frame and primary suspension. Similarity rules applied the method of S.D. Iwnicki from MMU, which is mainly aimed to study stability of bogie and characteristics of dynamic behavior and was designed as a $1 / 5$ scaled model to the actual bogie.

Design specification of small scaled bogie applied by data from the MAN bogie such as dimension, physical characteristics and each parameter are specified on Table 3.

\subsubsection{Design of primary suspension}

On designing 1/5 small scaled bogie, efforts were made to project stiffness on primary suspension and damper characteristics as close as possible from actual bogie. The MAN bogie, the motor bogie of Saemaeul, supports bogie frame by a pair of coil spring installed in wheelest and the elasticity of spring controls by axle box that installed between wheelest and bogie frame. The leaf spring link that installed on both sides of wheelest has no friction points and has horizontal stiffness and it conveys acceleration / deceleration force to wheelest while vehicle is running [3].

On one end of this device is fixed by bolts on sawtooth side to bogie frame and the other end is attached to the axle by using Rubber bonded bush with certain amount of flexibility.

Stiffness value of leaf spring and coil spring have been decided as Table 4 to project the primary suspension in 1/5 small scaled bogie. Primary spring constant $\mathrm{K}_{\mathrm{x}}, \mathrm{K}_{\mathrm{y}}$ from scaled bogie is considered as leaf spring and $\mathrm{K}_{\mathrm{z}}$ is considered as coil spring.

After analyzing data from previous model, it was confirmed that bushing is a factor affecting dynamic behavior of bogie. Therefore spring value was decided considering spring factor applied similarity rules from scaled bogie along with bushing spring value.

Table 4 Primary Suspension Design Data

\begin{tabular}{ccccc}
\hline \multirow{2}{*}{ Order } & Item & \multicolumn{3}{c}{ Formula } \\
\cline { 3 - 5 } & & $\begin{array}{c}\text { Spring } \\
(\mathrm{MN} / \mathrm{m})\end{array}$ & $\begin{array}{c}\text { Bushing } \\
(\mathrm{MN} / \mathrm{m})\end{array}$ & $\begin{array}{c}\text { Result } \\
(\mathrm{MN} / \mathrm{m})\end{array}$ \\
\hline 1 & $\mathrm{~K}_{\mathrm{x}}$ & 0.003032 & 0.128 & $\begin{array}{c}0.003032+(0.128 / 2) \\
=0.067032\end{array}$ \\
\hline 2 & $\mathrm{~K}_{\mathrm{y}}$ & 0.003032 & 0.032 & $\begin{array}{c}0.003032+(0.032 / 2) \\
=0.019032\end{array}$ \\
\hline 3 & $\mathrm{~K}_{\mathrm{z}}$ & 0.006064 & 0.001136 & $\begin{array}{c}0.006064+(0.001136 / 2) \\
=0.006632\end{array}$ \\
\hline - Note : Leaf spring $\left(\mathrm{K}_{\mathrm{x}}, \mathrm{K}_{\mathrm{y}}\right)$ & $2 \mathrm{ea}, \mathrm{Coil}$ spring $\left(\mathrm{K}_{\mathrm{z}}\right) 2 \mathrm{C}$
\end{tabular}

- Note : Leaf spring $\left(\mathrm{K}_{\mathrm{x}}, \mathrm{K}_{\mathrm{y}}\right)$ 2ea, Coil spring $\left(\mathrm{K}_{\mathrm{z}}\right)$ 2ea

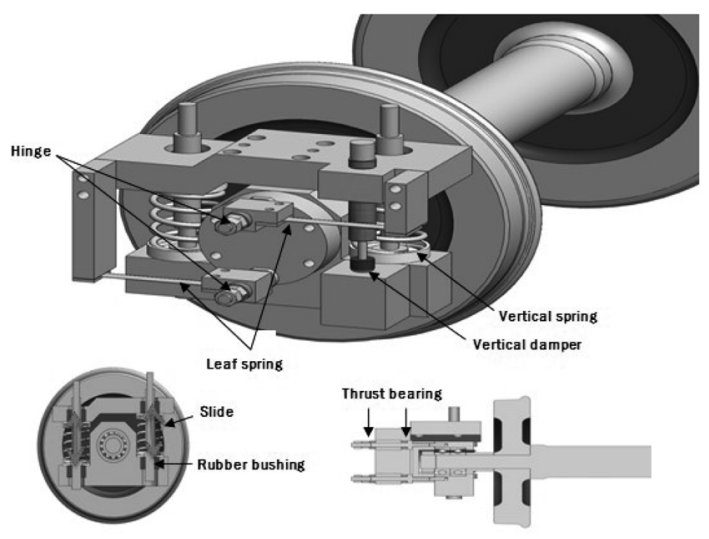

(a) 3D model of scaled bogie

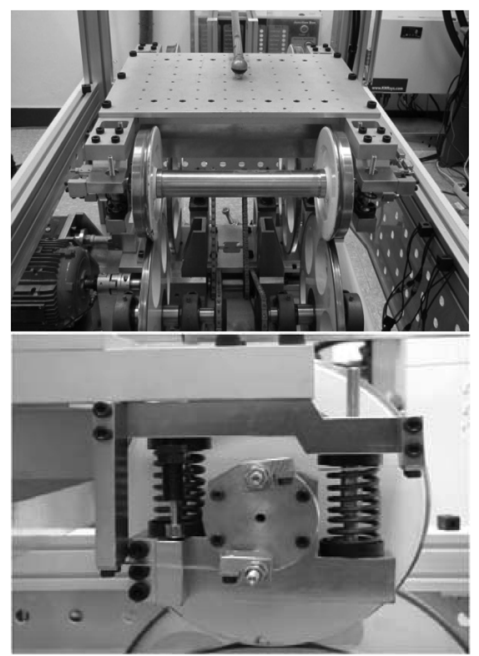

(b) Actual photos of scaled bogie

Fig. 5 Primary suspension of scaled bogie

3D model of $1 / 5$ scaled bogie was completed referring to designing data applied by similarity rules mentioned above and Fig. 5 shows the manufacturing process of scaled bogie that leaf spring factor was considered.

\subsubsection{Design of carbody weight}

Pneumatic has been used to reflect the weight of carbody in designing $1 / 5$ small scaled bogie.

As appeared in Fig. 6 (a), pressure, weight controlling, can be controlled by regulator after generating air pressure using air compressor. Also, a method that transfers weight of bogie through cylinder adjusting direction of pressure by using 3port hand valves was applied.

Also, efforts have been made not to affect restraint of the dynamic behavior of scaled bogie using ballpoint joint on the top and bottom of pneumatic cylinder. Fig. 6 (b) shows the device for weight of carbody. 


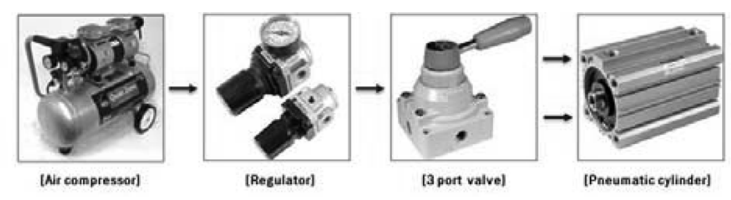

(a) Pneumatic cylinder

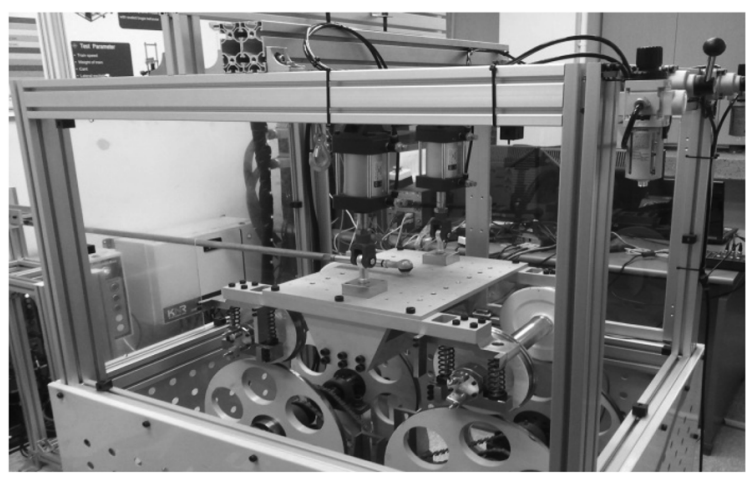

(b) Actual photos of pneumatic cylinder

Fig. 6 1/5 scaled bogie designing considering weight

\section{Conclusion}

The present work on the design of small scaled derailment simulator based on similarity laws as means of predicting the dynamic behavior of railway vehicle has yielded the following conclusions.

1. Small scaled derailment simulator consists of 5 elements, which are main equipment, HPU, HSM, chiller and controller part. The simulator was designed to test the dynamic behavior and stability of the bogie for changing attack angle, wheelbase and cant.

2. In designing a 1/5 small scaled bogie, MAN bogie, a bolsterless type from Saemaeul motor bogie, was used and it was scaled at $1 / 5$ by applying appropriate similarity laws.

3. Leaf spring which is similar to the actual MAN bogie has been deployed to design the primary suspension of a small scaled bogie and it was designed to project the weight of carbody using pneumatic cylinder.

4. The testing device developed here can be used to test the dynamic behavior and stability of scaled bogie, and will also allow us to conduct various investigations critical to safety and comfort including derailment, reduction of vibration, interface between wheel and rail, etc.

\section{References}

1. A. Jaschinski, etc (1999). "The application of roller rig to railway vehicle dynamics," Vehicle System Dynamics, Vol 31, Issue 5\&6, pp. 345-392.

2. Eom, B. G. and Lee, H. S. (2010). "Assessment of running safety of railway vehicles using multibody dynamics," International Journal of Precision Engineering and Manufacturing, Vol. 11, No. 2, pp. 315-320.

3. Korail Vehicle Dept (1992). "Inspection guideline for front and back powered Saemaeul motor bogie (DHC)".

4. Kim, H. C., Kim J. T., Lee, H. S. and Oh, S. B. (2008). "Basic design of vehicle simulator applying similarity rules," Spring Conference of the Korean Society for Noise and Vibration Engineering, pp.951-956.

Received(June 24, 2011), Accepted(June 26, 2011) 